\title{
Phosphate-induced changes in fatty acid biosynthesis in Chlorella sp. KS-MA2 strain
}

\author{
Aziz Ahmad ${ }^{1 *}$, Siti Mariam Osman ${ }^{1}$, Thye San Cha ${ }^{2}$, Sow Hong LoH ${ }^{1}$ \\ ${ }^{1}$ Universiti Malaysia Terengganu, School of Fundamental Sciences, Center for Fundamental and Liberal Education, \\ Kuala Terengganu, Malaysia \\ ${ }^{2}$ Universiti Malaysia Terengganu, Institute of Marine Biotechnology, Kuala Terengganu, Malaysia
}

\begin{abstract}
Phosphate is involved in fatty acid biosynthesis in microalgae cells. The influence of phosphate concentrations on polyunsaturated fatty acids' profile, elongation, and desaturation of fatty acids chains during their biosynthesis still remains unclear. Protein ketoacyl-ACP synthase-I ( $K A S-1)$ is required for the addition of malonyl-CoA for the elongation of butyryl-ACP from a 4- to 14-carbon chain. The omega-6 ( $\omega-6 F A D)$ and omega-3 desaturases $(\omega-3$ $F A D$ ) are involved in the insertion of double bonds into the pre-formed fatty acid chains. This study reports the effect of phosphate concentrations on the growth, fatty acid content, and level of $K A S-1, \omega-6 F A D$, and $\omega-3 F A D$ transcripts in Chlorella KS-MA2 strain at the stationary growth phase. Phosphate was tested at concentrations $9,18,36$, and $72 \mu \mathrm{M}$ and the fatty acid content was analyzed using gas chromatography. Gene expression levels were measured using quantitative real-time-PCR. Results showed that cell growth, amount of saturated fatty acids (SFA), monounsaturated fatty acids (MUFA), and polyunsaturated fatty acids (PUFAs) did not significantly $(P>0.05)$ differ among tested treatments. The highest concentration of $\alpha$-linolenic acid and the expression level of $\omega-3 F A D$ were recorded with $72 \mu \mathrm{M}$ of phosphate in culture medium. The KAS- 1 and $\omega-6 F A D$ transcripts levels decreased when the concentration of phosphate was below $36 \mu \mathrm{M}$. Phosphate in $\mathrm{F} / 2$ medium was sufficient to enhance the biosynthesis of major fatty acids in Chlorella sp.
\end{abstract}

Key words: fatty acids, phosphate limitation, Chlorella, $\alpha$-linolenic acid, desaturase

\section{Introduction}

Microalgae contains significant quantities of lipids that are far more superior to those contained in vegetable oil (Duong et al., 2015). Demands for microalgae as food, animal feed supplements, feedstock, and biofuel are increasing tremendously in the past years (Wacker et al., 2016). Moreover, microalgae are the primary source of omega-3 long-chain polyunsaturated fatty acid (PUFAs) in the marine food web. Chlorella is one of the microalgae species that is commercially utilized for its high level of chlorophyll, proteins, carbohydrates, vitamins, essential amino acids, enzymes, and fatty acids (Rasala and Mayfield, 2015). The major lipids in Chlorella are similar to those of other algae, but the nutritional requirements and fatty acids produced vary between species (Duong et al., 2015). Lipids and oils in Chlorella are deposited mainly in the form of triacylglycerols
(TAGs), which originate from de novo fatty acid synthesis (Jusoh et al., 2015). Green algae usually use the prokaryotic pathway to synthesize chloroplast lipids. The Chlorella species was concluded to be more similar to higher plants; it uses both eukaryotic and prokaryotic pathways to synthesize chloroplast lipids. Nonetheless, the biosynthetic pathways, enzymes, and regulatory factors involved in fatty acids and TAGs accumulation in microalgae remain largely unknown. Most of the understanding on microalgae lipid metabolism is based on the evolutionary conserved sequence homology of genes and enzymes involved in the lipid metabolism between algae and higher plants. The success of algae-based industrial products is based on the high biomass productivity and quality combined with low production costs (Abu-Ghosh et al., 2016). The biomass productivity is closely interrelated with the amount of light energy received and 
stored in the form of ATP and NADPH in the algal cells (Chen et al., 2015; Liu et al., 2012). Cell division is an energy-consuming process and microalgae tend to accumulate large amounts of energy before proliferation occur. In addition, Chlorella is also known to be sensitive to the changes in the abiotic and biotic factors in culture conditions. Thus, suitability of microalgae species, adequate cultural methods, ability to grow rapidly, and accumulation of large amounts of lipids are important factors in increasing the economic feasibility of lipid production (Rawat et al., 2013; Feng et al., 2012) and reducing the financial burden on algal companies (Wang et al., 2013).

The energy storage materials, lipids and starch in particular, tend to accumulate in the algal cells under stress conditions, when cell growth stops (Chen et al., 2015). The manipulation of culture medium composition is one of the strategies for achieving higher production of the desired target compounds. Several factors such as nutrient stress (Cha et al., 2011; Feng et al., 2012; George et al., 2014; Prochazkova et al., 2014; Kamalanathan et al., 2015; Shen et al., 2016), light (Abu-Gosh et al., 2016; Cheirsilp and Torpee, 2012), osmotic stress, radiation, $\mathrm{pH}$, temperature, heavy metals, and other chemicals (Sharma et al., 2012) have been shown to increase the lipid content of microalgae. Phosphorous is an important macronutrient that contributes to various metabolic processes such as signaling pathways, energy generation, and photosynthesis. It is involved in the metabolism and developmental processes such as biosynthesis of ATP, nucleotides, phospholipids, and other cellular components (Chen and Chen, 2006; Torres et al., 2009). It is also well established that algal growth rate depends on the phosphorus levels in cells (Larsdotter, 2006) and microalgae species. Variations in phosphate concentrations, described by Khozin-Goldberg and Cohen (2006), affected the accumulation of fatty acid and total oil production in Monodus subterraneus. However, the literature on the effect of phosphate on gene expression engaged in fatty acid biosynthesis in microalgae is limited.

In this study, various concentrations of phosphate were applied to Chlorella sp. KS-MA2 strain to analyze its effects on cell growth and total oil accumulation. Five major fatty acids (palmitic acid, stearic acid, oleic acid, linoleic acid, and $\alpha$-linolenic acid) and three fatty acid biosynthetic genes (ketoacyl-ACP synthase-I (KAS-1), omega- 6 desaturase $(\omega-6 F A D)$, and omega-3 desaturase
( $\omega-3 F A D)$ (Fig. 1) were analyzed to examine the relationships between gene regulation and fatty acid biosynthesis mediated by phosphate. Protein KAS- 1 is required for the addition of malonyl-CoA to elongate a 4-carbon fatty acid to 6-, 12-, and 16-carbon fatty acid chains (Kainou et al., 2006). KAS-2 catalyzes the production of 18-carbon fatty acid from 16-carbon fatty acid. Palmitic acid and stearic acid are the final products of fatty acid synthase (FAS). Fatty acid desaturase (FAD) enzymes are involved in the insertion of double bonds into the pre-formed fatty acid chains in reactions that require oxygen, $\mathrm{NADH}$, and cytochrome $b 5$ and reducing equivalent (Zhang et al., 2016). Omega-6 desaturase enzyme catalyzes the conversion of oleic acid into linoleic acid, while $\omega-3$ desaturase plays an important role in converting the $\omega-6$ fatty acids into $\omega-3$ fatty acids (Wang et al., 2013) and the desaturation of linolenic acid at the 15 th and 16 th positions to form a trienoic fatty acid, the $\alpha$-linolenic acid.

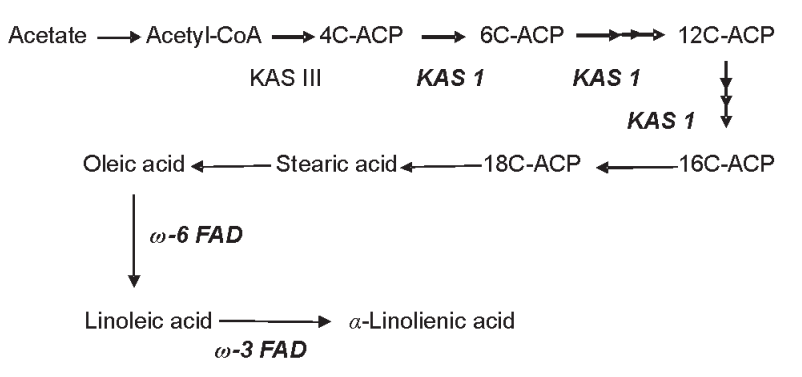

Fig. 1. The position of target genes; $K A S 1$, omega- $6 F A D$ and omega-3 $F A D$ in the fatty acid biosynthesis pathway

\section{Materials and methods}

A stock culture of mangrove-isolated Chlorella KSMA2 strain was obtained from the microalgae stock culture collection of the University Malaysia Terengganu, Malaysia. The Chlorella cells were maintained on $\mathrm{F} / 2$ medium (Guillard and Ryther, 1962) agar plates, which were prepared using natural seawater with salinity of $30 \mathrm{mgl}^{-1}$. Medium was solidified with $10 \mathrm{gl}^{-1}$ of bacteriological agar and sterilized by autoclaving at $121^{\circ} \mathrm{C}$ for $20 \mathrm{~min}$. A single colony was streaked onto a sterilized agar plate and subsequently incubated in a growth chamber at $25^{\circ} \mathrm{C}$ under 24 -hour white-light illumination with 55-70 $\mu \mathrm{mol}$ photons $\mathrm{m}^{-2} \mathrm{~s}^{-1}$ light intensity with constant aeration. This culture was considered as the Chlorella 
stock culture and was re-streaked onto a newly prepared agar plate every two months to maintain the cells.

\section{Phosphate treatment}

The initial cell density of each experiment was standardized at $5 \times 10^{6}$ cells ml $^{-1}$ and aseptically transferred into a freshly prepared treatment medium. The initial phosphate concentration of the treatment medium was adjusted to 9 (T1), 18 (T2), 36 (T3), and 72 (T4) $\mu \mathrm{M}$. T3 was a positive control, where phosphate at $36 \mu \mathrm{M}$ was the standard phosphate concentration in a $\mathrm{F} / 2$ medium. $\mathrm{T} 1$ and $\mathrm{T} 2$ were the limiting phosphate conditions, whereas T4 was the excess phosphate condition. The salinity level was adjusted to $30 \mathrm{mgl}^{-1}$. The cultures were maintained at $25^{\circ} \mathrm{C}\left( \pm 2^{\circ} \mathrm{C}\right)$ with continuous illumination with cool-white fluorescent lamps at a photon flux density of $55-70 \mu \mathrm{mol} \mathrm{m}^{-2} \mathrm{~s}^{-1}$ light intensity. The cell densities were measured every two days until a constant reading was obtained indicating that the cells had attained early stationary phase and the cells were then harvested. Three replicates were prepared for each treatment. During harvest cell number, biomass as dry weight, total oil, and fatty acid contents were determined. The cell number and absorbance at $600 \mathrm{~nm}$ were measured on a 10 -fold serial dilutions of culture broth using a hemocytometer (Neubauer) and BioPhotometer (Bio-Rad), respectively, each in triplicate. The cell density was calculated based on the plotted calibration curve at $600 \mathrm{~nm}$.

\section{Quantification of oil and fatty acids content}

The oil extraction and esterification of fatty acids into methyl esters (FAMEs) were carried out according to the modified methods of Cha and co-workers (2011). A sample of $500 \mathrm{mg}$ of dried Chlorella cells was vortexed in $10 \mathrm{ml}$ of $37 \%(\mathrm{v} / \mathrm{v}) \mathrm{HCl}$ for $3 \mathrm{~min}$ and boiled using the double-boiling technique for $30 \mathrm{~min}$. After cooling to room temperature, the mixtures were extracted with $25 \mathrm{ml}$ hexane for $1 \mathrm{~min}$ and then twice with $15 \mathrm{ml}$ hexane. The extraction solvents were combined. The hexane residue was vaporized with a Rotavapor R-210/215 (Buchi). The extracted oil was incubated at $80^{\circ} \mathrm{C}$ until a constant weight was achieved. FAMEs were analyzed using a chromatograph (GC-6890, Agilent) equipped with a flame ionization detector fitted with a capillary column (DB-225MS, Supelco). The injector temperature was set at $250^{\circ} \mathrm{C}$ and the flow rate of helium carrier gas (He) was $2 \mathrm{ml} \mathrm{min}^{-1}$. The flow rate of $\mathrm{H}_{2}$ gas and air were 35 and $350 \mathrm{ml} \mathrm{min}^{-1}$, respectively. The temperatures were programmed as follows: an initial temperature of $35^{\circ} \mathrm{C}$ for $0.5 \mathrm{~min}$; then increased to $195^{\circ} \mathrm{C}$ at a rate of $25^{\circ} \mathrm{C} \mathrm{min}^{-1}$; subsequently increased to $205^{\circ} \mathrm{C}$ at a rate of $3^{\circ} \mathrm{C} \mathrm{min}^{-1}$; and finally increased to $320^{\circ} \mathrm{C} \mathrm{min}^{-1}$ at a rate of $8^{\circ} \mathrm{C} \mathrm{min}^{-1}$ and held for $6.64 \mathrm{~min}$. Fatty acid components were identified by comparing their retention times and fragmentation patterns with established standards. The Supelco 37 Component FAME reference standard mix (Sigma-Aldrich) was used to identify and quantify the percentage of cis- and trans-fatty acid isomers in the samples.

\section{Studies of gene expression levels using quantitative real-time PCR}

Total RNA was isolated with GF-1 Total RNA Extraction Kit (Vivantis) according to the manufacturer's instructions and treated with DNase I (Fermentas) to remove the contaminating DNA. RNA isolates were confirmed to be DNA-free by PCR amplification of $18 S \mathrm{rDNA}$ gene. Subsequently, $1 \mu \mathrm{g}$ of RNA was reverse transcribed with iScript Reverse Transcription Supermix (BioRad) according to the manufacturer's instructions. The cDNA generated was directly used for the quantitative real-time PCR, which was performed in a MyiQ Single Color Real-Time PCR Detection System (Bio-Rad) using SYBR Green Real-Time PCR master mix (Bio-Rad) according to the manufacturer's instructions. The PCR mixture consists of cDNA (50 ng, $1 \mu \mathrm{l}$ ), $0.4 \mu \mathrm{M}$ final concentration of each forward $(\mathrm{F})$, and reverse $(\mathrm{R})$ primers (Table 1), $10 \mu 12 \times \mathrm{iQ}$ SYBR Green Supermix and nuclease-free water to the final volume of $20 \mu \mathrm{l}$. After heating the mixtures at $95^{\circ} \mathrm{C}$ for $15 \mathrm{~s}$, the RT-PCR amplification was programmed for 40 cycles of $95^{\circ} \mathrm{C}$ for $35 \mathrm{~s}, 64.2^{\circ} \mathrm{C}$ for $35 \mathrm{~s}$, and $72^{\circ} \mathrm{C}$ for $30 \mathrm{~s}$. Specificity of all PCR amplifications was verified with melting curve calculation at the completion of each run, which was set from $55^{\circ} \mathrm{C}$ to $95^{\circ} \mathrm{C}$ at $0.5^{\circ} \mathrm{C}$ increment. The gene expression data was analyzed using the $2^{-\Delta \Delta \mathrm{Ct}}$ method (Schmittgen and Livak, 2008; Livak and Schmittgen, 2001). Data represent the fold change of increase or decrease of the target gene expression levels in the treated samples relative to the control sample and were normalized to the expression level of $18 s$ rRNA reference gene. 
Table 1. The forward and reverse primers for quantitative Real-Time PCR

\begin{tabular}{l|l|c}
\hline Primer name & \multicolumn{1}{|c}{ Primer sequence (5'-3') } & Size of amplicons (bp) \\
\hline 18 S F1 & $5^{\prime}$-CCT GCG GCT TAA TTT GAC TCA ACA CG-3' & 172 \\
\hline 18S R2 & 5'-TAG CAG GCT GAG GTC ACG TTC G-3' $^{\prime}$ & 151 \\
\hline KAS1 F5 & $5^{\prime}$-CCA TGA TTG GTC ATT GCT TGG GAG C-3' & \\
\hline KAS1 R5 & $5^{\prime}$-GCT CTT GCT TCA TGT TTG GGA CCA C-3' & 129 \\
\hline O6D F3 & $5^{\prime}$-CTT CAC CCA CGA AGG CAC AGG C-3' & \\
\hline O6D R3 & $5^{\prime}$-CCT GCA CAC TGC TGG GAA CG-3' & 162 \\
\hline O3D F2 & $5^{\prime}$-CAT GTT GAG AAC GAC GAG TCC TGG TAT C-3' & \\
\hline O3D R2 & $5^{\prime}$-GTC AAA GTG GGA GCC AGT CTT GC-3' & \\
\hline
\end{tabular}

\section{Data analysis}

The differences in total oil and fatty acid content among the phosphate treatment of the Chlorella strain were statistically analyzed with one-way ANOVA using SPSS version 16.0. (SPSS Student version 16.0). Significant differences of the means were identified with $\mathrm{Tu}$ key's test at $P=0.05$ (www.ibm.com/software/analytic/ spss).

\section{Results}

\section{Cell growth, density, and biomass}

As shown in Figure 2A, cells' density was influenced by phosphate concentrations four days after beginning the treatment. Cells under T1 growth conditions were faster in attaining the stationary growth phase, 14 days after culture initiation, whereas in $\mathrm{T} 4$ growth conditions cells reached the stationary phase last, after 22 days of starting the treatment. The stationary phase was also lengthened as the phosphate concentration increased. At the stationary phase, the highest cell density was observed in T2, T3, and T4 tested conditions, but did not significantly differ among each other $(P>0.05)$ (Fig. 2B). The cells' biomass was reduced in T1 and T2 phosphate-limiting conditions, it was 0.59 - and 0.87 -fold lower (respectively) than that observed in the T3 positive control. Nonetheless, there was no significant difference $(P>0.05)$ between T3 and T4 biomass (Fig. 2B).

\section{Total oil content and fatty acid composition}

Our results showed that total oil content in Chlorella KS-MA2 strain was significantly affected $(P<0.05)$ by
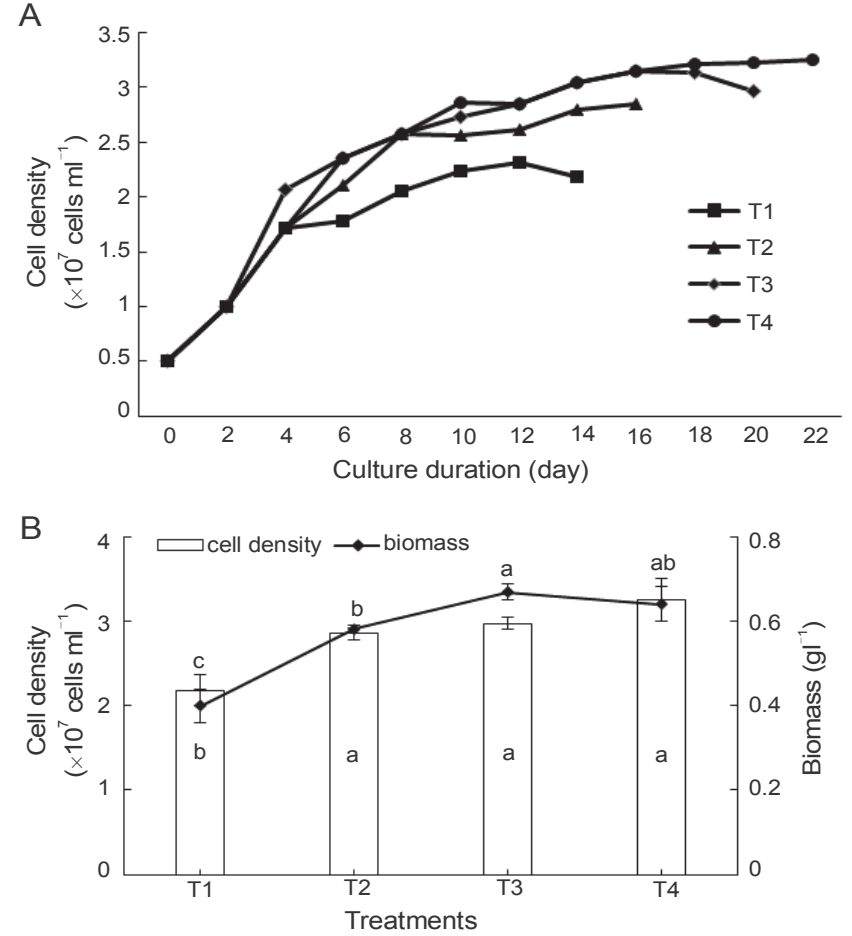

Fig. 2. Effects of phosphate concentrations on (A) growth (B) cell density and biomass at the early stationary phase of Chlorella strain KS-MA2 in modified F/2 medium. Bars represent the cell densities and lines represent biomass dry wt. Error bars represent the mean $\pm \mathrm{SD}(n=3)$. Values with the same letter were not significantly different by Tukey Test with $P=0.05$ significance level

different/tested phosphate concentrations (Fig. 3A). The highest total oil content was obtained in T3 $(27.52 \%$ $\pm 1.48 \%$ of biomass dry weight), where the phosphate concentration is equivalent to the $\mathrm{F} / 2$ medium. The total oil content was significantly reduced $(P<0.05)$ in higher phosphate condition (T4), 0.8-fold lower than that in T3. 
A

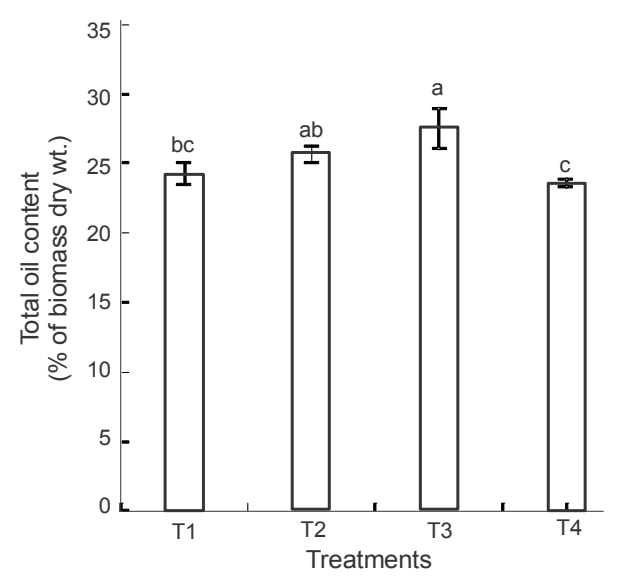

C

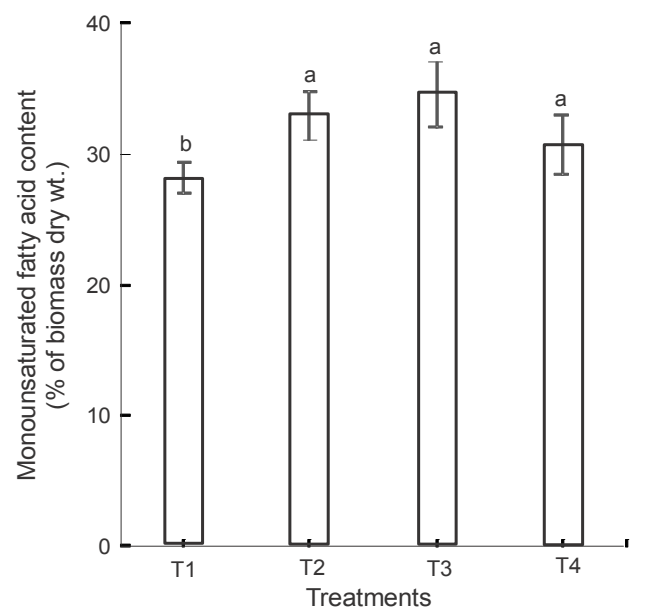

B

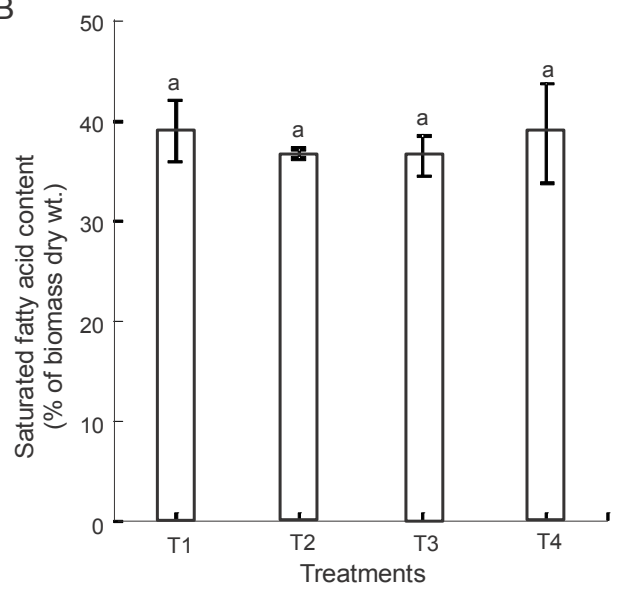

D

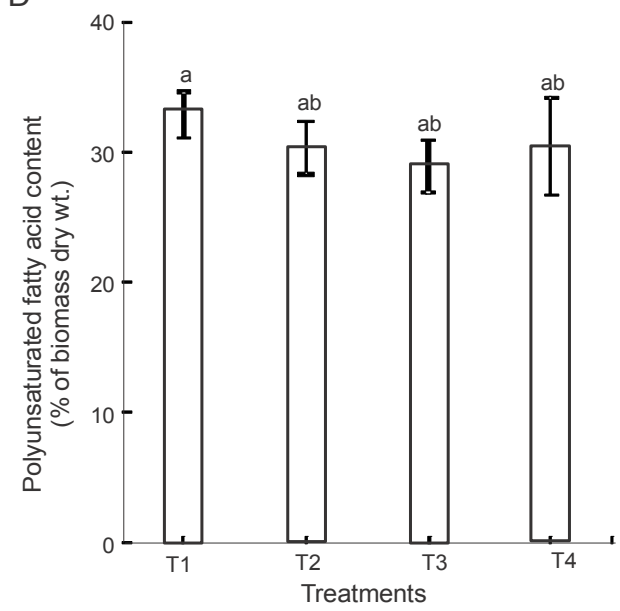

Fig. 3. Effects of phosphate concentrations on total oil (A) and fatty acid classes, the saturated fatty acid SFA (B), monounsaturated fatty acid MUFA (C) and polyunsaturated fatty acid PUFA (D) at early stationary phase of Chlorella strain KS-MA2 cultured in modified F/2 medium. Error bars represent mean $\pm \mathrm{SD}(n=3)$. Error bars represent the mean \pm SD $(n=3)$. Values with the same letter were not significantly different by Tukey Test with $p=0.05$ significance level

However, the saturated fatty acids (SFA) content was not significantly influenced $(P>0.05)$ by the phosphate concentrations (Fig. 3B), but they significantly influenced $(P<0.05)$ the amount of monounsaturated fatty acids (MUFA, Fig. $3 \mathrm{C}$ ) and polyunsaturated fatty acids (PUFA, Fig. 3D) in Chlorella sp. KS-MA2 strain. The highest MUFA content was obtained in T2, T3, and T4 treatments, but there was no statistically significant difference between them $(P>0.05)$. T1 phosphate-limiting conditions reduced MUFA content, it was 0.8 -fold lower than that in T3 $(34.57 \% \pm 2.5 \%$ of biomass dry weight). However, in the same tested conditions PUFAs content was increased by 1.13 -fold compared to T3 $(28.9 \% \pm 2.0 \%$ of biomass dry weight, Fig. 3D). These findings clearly show that fatty acid accumulation is affected by phosphate availability.
In our experiments, phosphate concentrations significantly affected $(P<0.05)$ the fatty acid composition in Chlorella sp. KS-MA2 strain as well (Fig. 4). The palmitic acid (Fig. 4A), oleic acid (Fig. 4C), and linoleic acid (Fig. 4D) contents did not significantly differ $(P>0.05)$ among the various treatments. Interestingly, the lowest palmitic acid was observed in T3, but it did not significantly differ $(P>0.05)$ from T2 or T4. The lowest oleic acid content was in $\mathrm{T} 1$, but it did not significantly differ $(P>0.05)$ when compared with T4. Interestingly, our results clearly demonstrate that phosphate-limiting conditions significantly influenced $(P<0.05)$ the stearic acid (Fig. 4B) and $\alpha$-linolenic acid (Fig. 4E) contents in KSMA2 Chlorella strain. T1 and T2 phosphate-limiting conditions reduced the stearic acid contents, they were 0.38 - and 0.33 -fold lower than that in T3 $(6.55 \% \pm 0.08 \%$ 
A

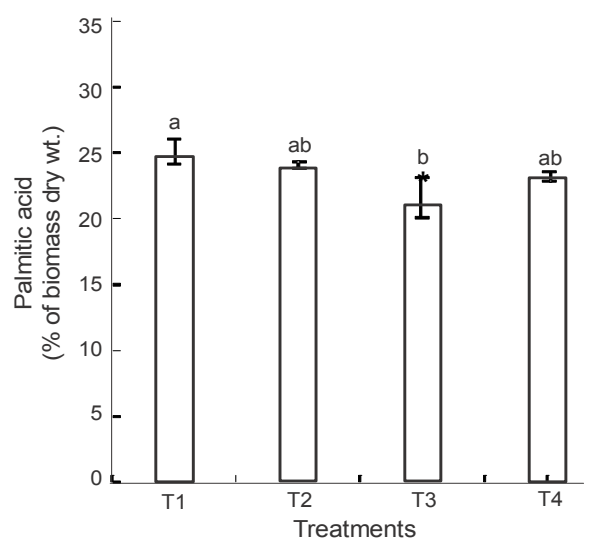

C

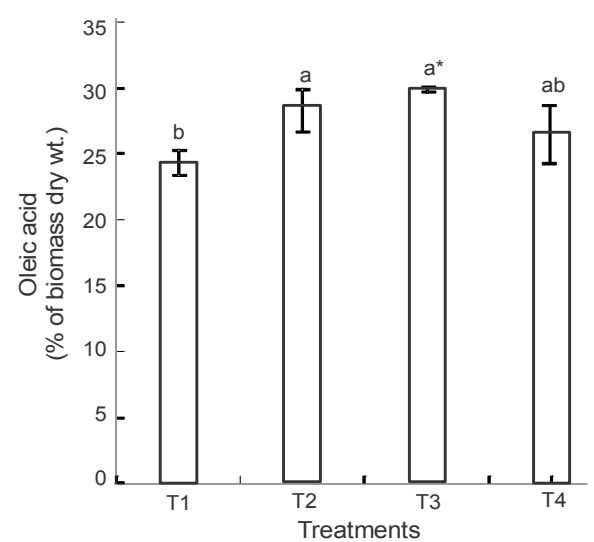

B

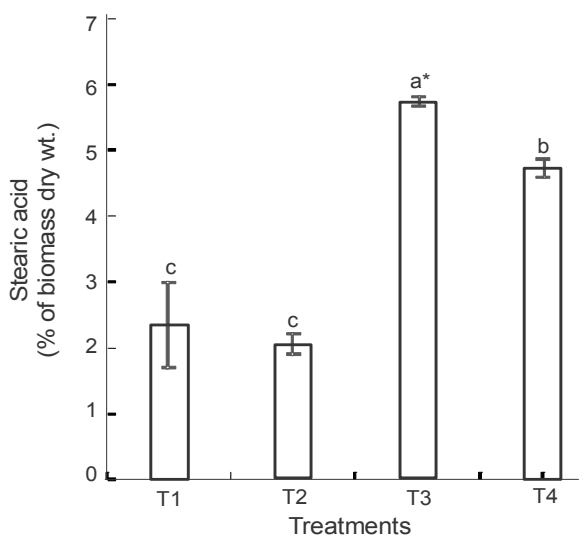

D

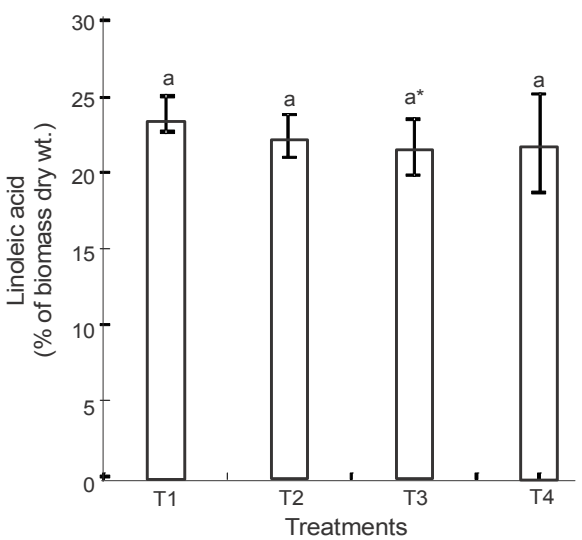

E

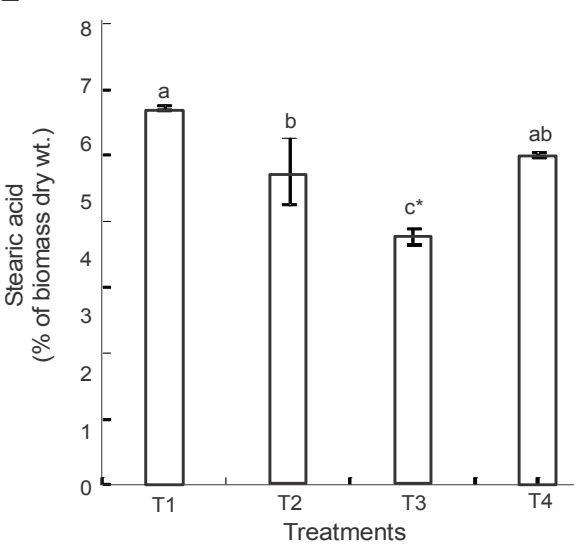

Fig. 4. Effects of phosphate concentrations on colour on the palmitic acid (A), stearic acid (B), oleic acid (C), linoleic acid (D) and linolenic acid (E) content at early stationary phase of Chlorella strain KS-MA2 cultured in F/ 2 medium. Error bars represent mean $\pm \mathrm{SD}(n=3)$. Values with the same letter were not significantly different by Tukey Test with $P=0.05$ significance level

of biomass dry weight), respectively. The highest $\alpha$-linolenic acid content was obtained in $\mathrm{T} 1$, it was 1.5 -fold higher than that in $\mathrm{T} 3(4.86 \pm 0.14 \%$ of biomass dry weight).

\section{Gene expression levels}

The gene expression analysis showed that $\mathrm{T} 1$ phosphate-limiting conditions significantly increased $(P<0.05)$ the expression levels of different genes engaged in lipid biosynthesis pathways (Fig. 5). The beta-ketoacyl synthase 1 (KAS-1), which catalyzes the elongation of fatty acid chains from butaryl-ACP to palmityl-ACP, was highly expressed $(P<0.05)$ in T1 and T4 (Fig. 5A), about 3.7and 4.3-fold higher than that in T3. The omega-6 desaturase $(\omega-6 F A D)$ involved in the transcripts of desaturase gene was highly expressed in $\mathrm{T} 1$, but its level did 
not significantly differ $(P>0.05)$ from T3. However, the omega-s desaturase ( $\omega-3 F A D)$ was highly expressed in both tested phosphate-limiting conditions, T1 and T2 (Fig. 5C), its expression was 2.24- and 3.17-fold higher than that in $\mathrm{T} 3$, respectively.

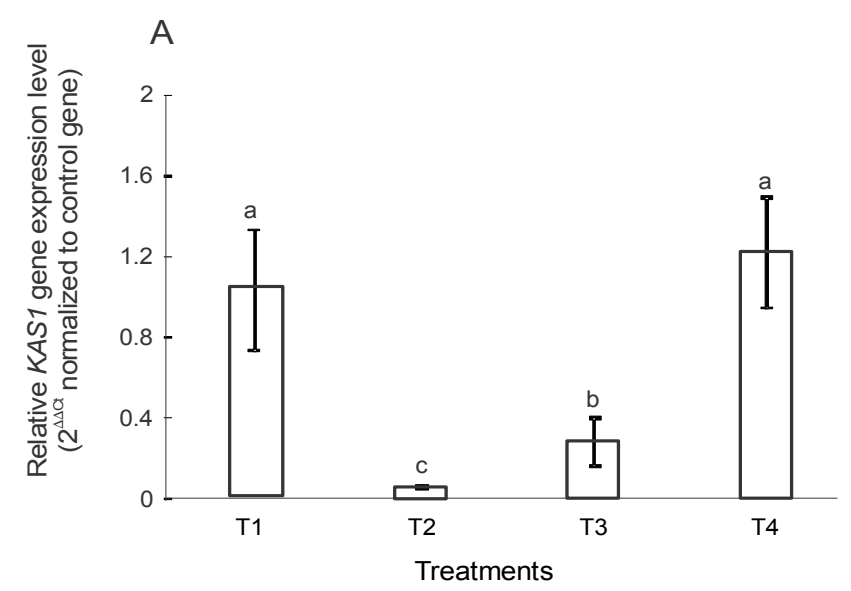

B

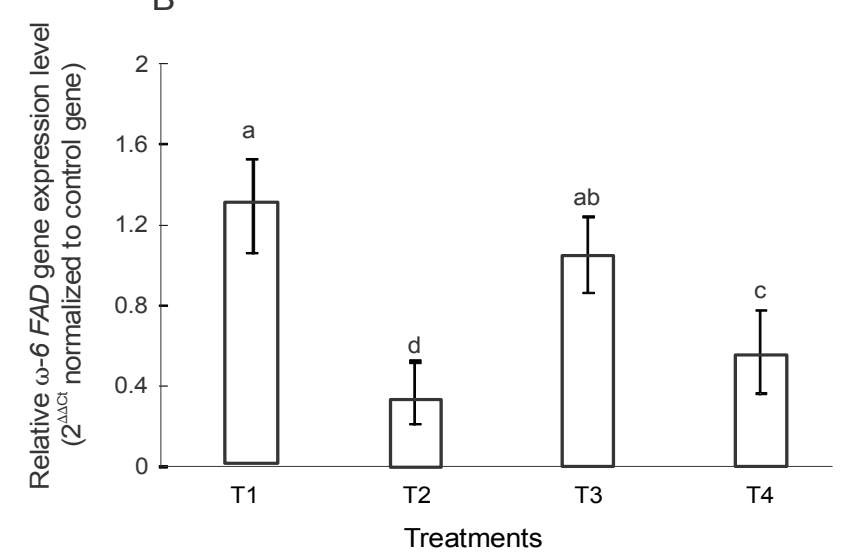

C

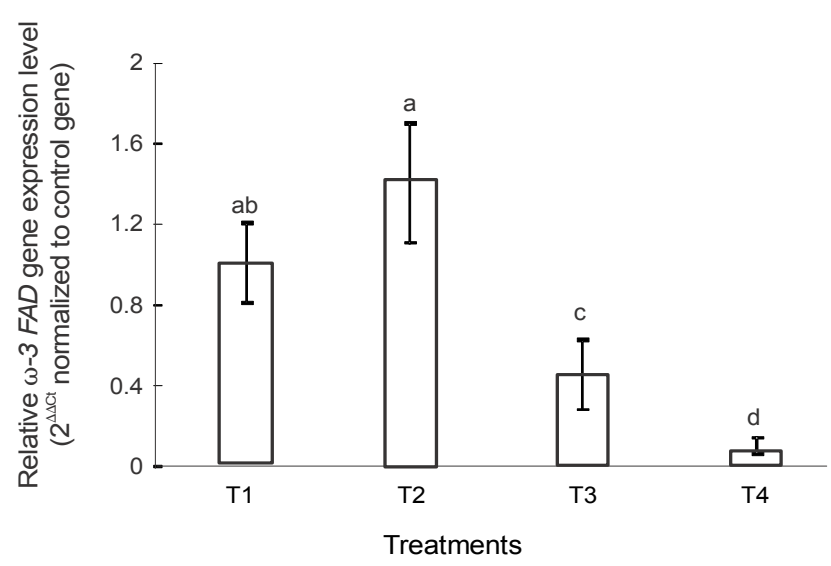

Fig. 5. Mean fold of relative gene expression of $K A S-1$ (A), $\omega-6$ $F A D(\mathrm{~B})$ and $\omega-3 F A D(\mathrm{C})$ genes of Chlorella sp strain KS-MA2 cultured in different phosphate concentrations. Fold change was relative to control treatment. Error bars represent mean $\pm \mathrm{SD}$ $(n=3)$. Values with the same letter were not significantly different by Tukey Test with $P=0.05$ significance level
Correlation analysis between gene expression and fatty acid profile under phosphate treatment

To study the relationship between gene expression and fatty acids profile, Pearson Correlation analysis was carried out and results were summarized in Table 2 . The biomass exhibited a high positive correlation with the expression level of KAS-1 $(0.905 ; P<0.01)$. The correlation between genes and individual fatty acids showed that expression of $K A S-1$ gene is positively correlated with stearic acid $(0.872 ; P<0.01)$. Another interesting finding is that the $\omega-6$ FAD gene expression had a positive correlation with total oil content $(0.748 ; P<0.05)$ and also highly correlated $(P<0.01)$ with MUFA, oleic acid, PUFA, and $\alpha$-linolenic acid (Table 2). However, the expression level of $\omega-3 \mathrm{FAD}$ under various phosphate concentrations did not correlate with biomass, total oil content, or fatty acid composition.

\section{Discussion}

The phosphate availability has a significant impact on the growth and propagation of Chlorella and broad effects on its lipid and FA composition. The inter-relationships between phosphorus availability and basic physiological processes such as growth, reproduction, photosynthesis, or respiration have also been reported in another microalgae species (Chen et al., 2015). Our findings on cell density and biomass (Fig. 2) were consistent with studies done by Feng and co-workers (2012) and Ying and Chang, (2009), who found that with the increase in the phosphate concentrations, cell density and biomass productivity of Chlorella zofingiensis and Isochrysis galbana did not increase, respectively. The biomass productivity and cell density are closely interrelated with the amount of energy received and stored in the form of carbohydrates and lipids (Chen et al., 2015). Microalgae have the ability to store excess phosphates within the cells in the form of polyphosphate granules (volutin) and later, during periods of phosphate limitation, use them for growth (Powell et al., 2008). It has been shown that the consumption of polyphosphates during phosphatelimiting conditions caused lower cell growth of Phaeocytis globosa when compared to direct usage of phosphates from the culture medium (Ghyoot et al., 2015). Phosphate limitation is known to decrease the Chlorella zofingiensis biomass (Feng et al., 2012), and also due to the reduction in nitrate uptake by the phosphate-limiting 
conditions, which affects cell proliferation (Xin et al., 2010). However, excess phosphate can cause phosphate toxicity in cells (Feng et al. 2012) reducing cell density and biomass (Fig. 2B). When cell division slows down, there is no requirement for the synthesis of new membrane compounds and instead cells divert fatty acids into TAG (Dean et al., 2008). Our results indicated that fatty acid biosynthesis catalyzed that by $K A S 1$ was highly correlated with Chlorella biomass (Table 2). Under normal growth conditions, ATP and NADPH produced during photosynthesis are consumed by generated biomass resulting in the formation of $\mathrm{ADP}$ and $\mathrm{NADP}^{+}$that are being available again as acceptor molecules in photosynthesis. It has been showed that cell growth and proliferation are impaired due to the lack of nutrients such as phosphate, thus the pool of $\mathrm{NADP}^{+}$electron acceptors for photosynthesis can be depleted. NADPH is consumed in FA biosynthesis which increased FAs production, and are stored as TAGs and replenishes the pool of $\mathrm{NADP}^{+}$under growth-limiting conditions. Photosynthesis is mainly controlled by the light abundances and cannot be shut down completely; this can lead to potentially dangerous situation for cell, damaging cell components (Sharma et al., 2012).

Table 2. Pearson's correlation coefficient between gene expression levels (KAS I, $\omega-6$ FAD and $\omega-3$ FAD), biomass, total oil content (oil), fatty acid classes (SFA, MUFA, and PUFA), and fatty acid compositions (palmitic acid, stearic acid, oleic acid, linoleic acid, and $\alpha$-linolenic acid)

\begin{tabular}{l|c|c|c}
\hline & $K A S-1$ & $\omega-6$ FAD & $\omega-3$ FAD \\
\hline Biomass & $0.905^{* *}$ & 0.205 & -0.625 \\
\hline Oil & -0.090 & $0.748^{*}$ & 0.177 \\
\hline SFA & -0.190 & -0.437 & 0.037 \\
\hline MUFA & 0.453 & $0.934^{* *}$ & -0.221 \\
\hline PUFA & -0.264 & -0.487 & 0.197 \\
\hline Palmitic acid & -0.587 & -0.550 & 0.129 \\
\hline Stearic acid & $0.872^{* *}$ & 0.290 & 0.028 \\
\hline Oleic acid & 0.514 & $0.901^{* *}$ & -0.163 \\
\hline Linoleic acid & -0.245 & -0.298 & 0.079 \\
\hline$\alpha$-Linolenic acid & -0.467 & $-0.886^{* *}$ & 0.103 \\
\hline
\end{tabular}

Single asterisks denote statistically significant correlation coefficients $(P<0.05)$, while double asterisks denote statistically significant correlation coefficients $(P<0.01)$.

Microalgae storage lipids are present mainly in the form of triacylglycerides (TAGs), which composes of saturated and/or unsaturated FAs. Our results on total lipid content (Fig. 3) was consistent with the data obtained by Mujtaba and co-workers (2012), where high lipid synthesis (contributed largely to the increased synthesis of palmitic and $\alpha$-linolenic acids) was observed when $C$. vulgaris was cultured in phosphate-limiting conditions. Nonetheless, MUFA presented mainly as oleic acid (Fig. 4C) was reduced under phosphate-limiting conditions. It has been also showed that the cellular lipid content of starved cells in Monodus subterraneous was increased due to the increase in the TAGs levels which at the same time decreased the production of phospholipids (Khozin-Goldberg and Cohen, 2006). This is consistent with the findings of Fidalgo and co-workers (1998), who stated that microalgae produce higher unsaturated fatty acid levels during stationary growth phase, where the nutrient concentration is limited. A similar finding was reported by Tan and Lin (2011) and KhozinGoldberg and Cohen (2006), who studied growth of Scenedesmus subterraneus and Monodus subterraneues.

The biosynthesis of unsaturated FAs is catalyzed by the desaturase enzymes, which are encoded by fatty acid desaturases (FAD) genes. A group of membrane bound desaturases and elongating enzymes are involved in the modification of saturated fatty acid precursors (palmitic acid and stearic acid) to PUFAs (Ruiz-Lopez et al., 2015). Our experiment demonstrated that phosphate concentration had a significant impact on the production of unsaturated FAs (Fig. 4) and the expression levels of omega-6 ( $\omega-6 F A D)$ and omega-3 desaturase ( $\omega-3 F A D$; Fig. 5) genes engaged in desaturation of fatty acids. Oleic acid is a substrate for $\omega-6 F A D$ enzymes to produce the linoleic acid. The latter is used to produce $\alpha$-linolenic acid in a reaction catalyzed by $\omega-3 F A D$ enzyme. Thus, the activation of $\omega-6 F A D$ is highly dependent on the availability of oleic and $\alpha$-linolenic acids (Fig. 4, Table 2), which suggests further that the function of desaturase in PUFA biosynthesis pathway is the fulfillment of the demand of membrane phospholipids. It is known that microalgae structural lipids typically have a high content of PUFAs (Sharma et al., 2012). In addition, phosphatelimitation affects the carbon metabolism and cell physiology regulation that increases cellular demand for the synthesis of membrane phospholipids (Romano et al., 2015).

It can be concluded that phosphate availability regulates the cell proliferation and the fatty acid profile in 
Chlorella sp. Phosphate-limiting conditions are an important factor in triggering the expression of fatty acid desaturase genes, which enhances the biosynthesis of PUFAs. It has been observed that $\mathrm{F} / 2$ medium with phosphate addition in concentrations smaller than $36 \mu \mathrm{M}$ is the most suitable for PUFAs production by Chlorella sp. KS-MA2 strain.

\section{Acknowledgments}

This work was supported by the Ministry of Agriculture (MOA), Malaysia (Science Fund Project no: 05-01-12-SF0007).

\section{References}

Abu-Ghosh S., Fixler D., Dubinsky Z., Iluz D. (2016) Flashing light in microalgae biotechnology. Bioresource Technol. 203: 357-363.

Cha T.S., Chen J.W., Goh E.G., Aziz A., Loh S.H. (2011) Differential regulation of fatty acid biosynthesis in two Chlorella species in response to nitrate treatments and the potential of binary blending microalgae oils for biodiesel application. Bioresource Technol. 102: 10633-10640.

Chen T., Liu J., Guo B., Ma X., Sun P., Liu B., Chen F. (2015) Light attenuates lipid accumulation while enhancing cell proliferation and starch synthesis in the glucose-fed oleaginous Chlorella zofingiensis. Sci. Rep. 5: 14936. Doi: $10.1038 /$ srep 14936.

Cheirsilp B., Torpee S. (2012) Enhanced growth and lipid production of microalgae under mixotrophic culture condition?: Effect of light intensity, glucose concentration and fed-batch cultivation. Bioresource Technol. 110: 510-516.

Chen G.Q., Chen F. (2006) Growing phototrophic cells without light. Biotechnol. Lett. 28: 607-616.

Dean A.P., Nicholson J.M., Sigee D.C. (2008) Impact of phosphorus quota and growth phase on carbon allocation in Chlamydomonas reinhardtii: an FTIR microspectroscopy study. Eur. J. Phycol. 43(4): 345-354.

Duong V. T., Ahmed F., Thomas-Hall S.R., Quigley S., Nowak E., Schenk P.M. (2015) High protein- and high lipid-producing microalgae from Northern Australia as potential feedstock for animal feed and biodiesel. Front Bioeng. Biotechnol. 3: 1-7. Doi: 10.3389/fbioe.2015.00053.

Feng P., Deng Z., Fan L., Hu Z. (2012) Lipid accumulation and growth characteristics of Chlorella zofingiensis under different nitrate and phosphate concentrations. J. Biosci. Bioengineer. 114(4): 405-410.

Fidalgo J.P., Cid A., Torres E., Sukenik A., Herrero C. (1998) Effects of nitrogen source and growth phase on proximate biochemical composition, lipid classes and fatty acid profile of the marine microalga Isochrysis galbana. Aquaculture 166: 105-116.

George B., Pancha I., Desai C., Chokshi K., Paliwal C., Ghosh T., Mishra S. (2014) Effects of different media composition, light intensity and photoperiod on morphology and physiology of freshwater microalgae Ankistrodesmus falcatus-a potential strain for bio-fuel production. Bioresour. Technol. 171: 367-374.

Ghyoot C., Gypens N., Flynn K.J., Lancelot C. (2015) Modelling alkaline phosphatase activity in microalgae under orthophosphate limitation: the case of Phaeocytis globose. J. Planton Res. 37(5): 869-885.

Guillard R.R.L., Ryther J.H. (1962) Studies of marine planktonic diatoms. I. Cyclotella nana Hustedt and Detonula confervacea Cleve. Can. J. Microbiol. 8: 229-239.

Jusoh M., Loh S.W., Chuah T.S., Aziz A, Cha T.T. (2015) Elucidating the role of jasmonic acid in oil accumulation, fatty acid composition and gene expression in Chlorella vulgaris (Trebouxiophyceae) during early stationary growth phase. Algal Res. 9: 14-20.

Kamalanathan M., Pierangelini M., Shearman L.A., Gleadow R., Beardall J. (2015) Impacts of nitrogen and phosphorus starvation on the physiology of Chlamydomonas reinhardtii. J. Appl. Phycol. Doi: 10.1007/s10811-015-0726-y.

Kainou K., Kamisaka Y., Kimura K., Uemura, H. (2006) Isolation of $\Delta 12$ and $\omega 3$-fatty acid desaturase genes from the yeast Kluyveromyces lactis and their heterologous expression to produce linoleic and $\alpha$-linolenic acids in Saccharomyces cerevisiae. Yeast 23: 605-612. Doi: 10.1002/yea.1378.

Khozin-Goldberg I., Cohen Z. (2006) The effect of phosphate starvation on the lipid and fatty acid composition of the fresh water eustigmatophyte Monodus subterraneus. Phytochemistry 67: 696-701.

Larsdotter K. (2006). Wastewater treatment with microalgae A literature review. VATTEN. 62: 31-38.

Liu J., Yuan C., Hu G., Li F. (2012) Effects of light intensity on the growth and lipid accumulation of microalgae Scenedesmus sp. 11-1 under nitrogen limitation. Appl. Biochem. Biotechnol. 166: 2127-2137.

Livak K.J., Schmittgen T.D. (2001) Analysis of relative gene expression data using real-time quantitative PCR and the $2^{\triangle \Delta C t}$ method. Appl. Biosystem. 25: 402-408.

Mujtaba G., Choi W., Lee C.G., Lee K. (2012) Lipid production by Chlorella vulgaris after a shift from nutrient-rich to nitrogen starvation conditions. Bioresource Technol. 123: 279-283.

Powell N., Shilton A.N., Pratt S., Chisti Y. (2008) Factors influencing luxury uptake of phosphorous by microalgae in waste stabilization ponds. Environ. Sci. Technol. 42: 59585962.

Prochazkova G., Branyikova I., Zachleder V., Branyik T. (2014) Effect of nutrient supply status on biomass composition of eukaryotic green microalgae. J. Appl. Phycol. 26: 1359-1377.

Rawat I., Kumar R.R., Mutanda T., Bux F. (2013) Biodiesel from microalgae: A critical evaluation from laboratory to large scale production. Appl. Energy, 103: 444-467.

Rasala B.A., Mayfield S.P. (2015) Photosynthetic biomanufacturing in green algae; production of recombinant proteins for industrial, nutritional, and medical uses. Photosynthesis Res. 123(3): 227-239. 
Romano S., Schulz-Vogt H.N., González J.M. Bondarev V. (2015) Phosphate limitation induces drastic physiological changes, virulence related gene expression and secondary metabolite production in strain Pseudovibrio sp. FOBEG1. Appl. Environ. Microbiol. 81 (10): 3518-3528. Doi: 10.1128/AEM.04167-14.

Ruiz-Lopez N., Usher S., Syanova O.V., Napier J.A., Haslam R.P. (2015) Modifying the lipid content and composition of plant seeds: engineering the production of LC-PUFA. Appl Microbiol Biotechnol (2015) 99:143-154. DOI 10.1007/s00253-014-6217-2.

Schmittgen T.D, Livak K.J. (2008) Analyzing real-time PCR data by the comparative CT method. Nature Protocols. 3, 1101-1108.

Sharma K.K., Schuhmann H., Schenk P.M. (2012) High lipid induction in Microalgae for biodiesel production. Energies. 5: 1532-1553. Doi: 10.3390/en5051532.

Shen X.F., Liu J.J., Chauhan A.S., Hu H., Ma L.L., Lam P.K.S., Raymond J., Zeng R.J. (2016) Combining nitrogen starvation with sufficient phosphorus supply for enhanced biodiesel productivity of Chlorella vulgaris fed on acetate. Algal Research 17:261-267. 2016.

Tan Y., Lin J. (2011) Biomass production and fatty acid profile of a Scenedesmus rubescens-like microalga. Bioresource Technol. 102: 10131-10135.

Torres C.A.P., Bucio J.L. Estrella L.H. (2009) Low phosphate signalling induces changes in cell cycle gene expression by increasing auxin sensitivity in the Arabidopsis root system. Plant Signal. Behaviour. 4(8): 781-783.
Wacker A., Piepho M., Harwood J.L., Guschina I.A., Arts M.T. (2016) Light-induced changes in fatty acid profile in specific lipid classes in several freshwater phytoplankton species. Front. Plant Science. 7: 264. Doi: 10.3389/fpls. 2016.00264 .

Wang M., Chen H., Gu Z., Zhang H., Chen W., Chen Y.Q. (2013) $\omega 3$ fatty acid desaturases from microorganisms: structure, function, evolution, and biotechnological use. Appl Microbiol. Biotechnol. 97(24): 10255-10262. Doi: 10.1007/s00253-013-5336-5.

Xin L., Hong Y.H., Ke, G., Ying X.S. (2010) Effect of different nitrogen and phosphorus concentrations on the growth, nutrient uptake and lipid accumulation of a freshwater microalgae Scenedesmus sp. Bioresource Technol. 101: 5494-5500.

Ying Y.S., Chang H.W. (2009) The optimal growth conditions for the biomass production of Isochrysis galbana and the effect that phosphorus, $\mathrm{Zn}^{2+}, \mathrm{CO}_{2}$, and light intensity have on the biochemical composition of Isochrysis galbana and the activity of extracellular CA. Biotechnol. Bioprocess Engineer. 14: 225-231.

Zhang Y., Wang H., Zhang J., Hu Y., Zhang L., Wu X., Su X., Li T., Zou X., Liang B. (2016) The cytochrome b5 reductase HPO-19 is required for biosynthesis of polyunsaturated fatty acids in Caenorhabditis elegans. Biochim Biophys Acta. 1861(4): 310-9. Doi: 10.1016/j.bbalip.2016.01.009. 